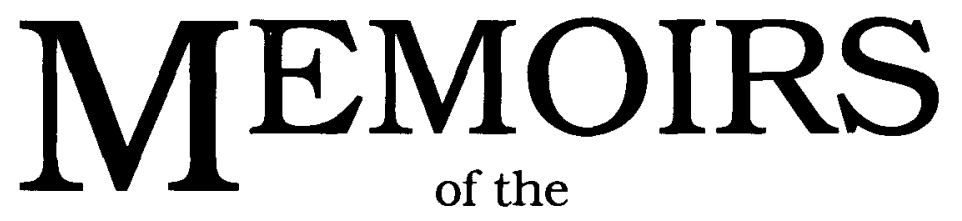

American Mathematical Society

Number 556

\title{
Finite Rational Matrix Groups
}

\author{
G. Nebe \\ W. Plesken
}

July 1995 • Volume 116 - Number 556 (third of 4 numbers) • ISSN 0065-9266 


\section{Table of Contents}

Finite rational matrix groups 1

I. Introduction 1

II. Notation, basic definitions, and constructions 4

III. Methods

IV. Odd dimensions $\quad 19$

V. Groups of type $L_{2}(p)$ of degree $p \pm 1$

VI. Dimensions $2 p$

VII. Dimension 12

VIII. Dimension 18

IX. Dimension $20 \quad 49$

Appendix: The Gram matrices fixed by the primitive r.i.m.f. groups of degree $n=12,14,15,18,20,21$ and $22 \quad 64$

$\begin{array}{ll}\text { List of notations } & 70\end{array}$

$\begin{array}{ll}\text { References } & 72\end{array}$

$\begin{array}{ll}\text { Finite rátional matrix groups of degree } 16 & 74\end{array}$

$\begin{array}{ll}\text { I. Introduction } & 74\end{array}$

$\begin{array}{ll}\text { II. Methods: Invariant quadratic forms and subgroups } & 76\end{array}$

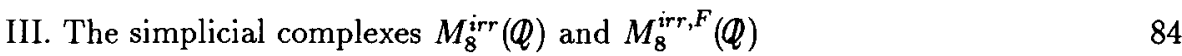

IV. Results in dimension $16 \quad 86$

V. Determination of the primitive r.i.m.f. groups of degree $16 \quad 90$

VI. The simplicial complexes $M_{16}^{i r r}(Q)$ and $M_{16}^{i r r, F}(\Phi)$

Appendix: The Gram matrices fixed by the primitive r.i.m.f.

$\begin{array}{ll}\text { groups of degree } 16 & 141\end{array}$

$\begin{array}{ll}\text { References } & 144\end{array}$

vii 